\title{
EXISTENCE OF SOLUTIONS FOR A SECOND ORDER DISCRETE BOUNDARY VALUE PROBLEM WITH MIXED PERIODIC BOUNDARY CONDITIONS
}

\begin{abstract}
MIN WANG
ABSTRACT. In this talk, a second order discrete boundary value problem with a pair of mixed periodic boundary conditions is considered. Sufficient conditions on the existence and multiplicity of solutions are obtained by using variational methods. A particular Banach space and an associated functional are presented to overcome the asymmetry of the mixed periodic boundary conditions. Examples are also given to illustrate the applications of the main result.
\end{abstract}

Department of Mathematics, Kennesaw State University, Marietta, GA 30060, USA.

E-mail address: min.wang@kennesaw.edu 